\title{
Effects of ouabain on vascular reactivity
}

\section{D.V. Vassallo ${ }^{1}$ \\ E. Songu-Mize ${ }^{2}$, \\ L.V. Rossoni ${ }^{1}$ \\ and S.M.C. Amaral ${ }^{1}$}

\author{
1Departamento de Ciências Fisiológicas, Centro Biomédico, \\ Universidade Federal do Espírito Santo, 29040-095 Vitória, ES, Brasil \\ ${ }^{2}$ Department of Pharmacology and Experimental Therapeutics, \\ Louisiana State University Medical Center, New Orleans, LA 70112-1393, USA
}

\author{
Correspondence \\ D.V. Vassallo \\ CBM/UFES \\ Av. Marechal Campos, 1468 \\ 29040-095 Vitória, ES \\ Brasil \\ Presented at the International \\ Symposium "Neuroendocrine \\ Control of Body Fluid Homeostasis", \\ Ribeirão Preto, SP, Brasil, \\ August 17-20, 1996. \\ Research supported by CNPq \\ (No. 521.552/93-1) and FINEP \\ (No. 66.93.0036.00).
}

Received November 29, 1996 Accepted January 6, 1997

\begin{abstract}
Ouabain is an endogenous substance occurring in the plasma in the nanomolar range, that has been proposed to increase vascular resistance and induce hypertension. This substance acts on the $\alpha$-subunit of $\mathrm{Na}^{+}, \mathrm{K}^{+}$-ATPase inhibiting the $\mathrm{Na}^{+}$-pump activity. In the vascular smooth muscle this effect leads to intracellular $\mathrm{Na}^{+}$accumulation that reduces the activity of the $\mathrm{Na}^{+} / \mathrm{Ca}^{2+}$ exchanger and to an increased vascular tone. It was also suggested that circulating ouabain, even in the nanomolar range, sensitizes the vascular smooth muscle to vasopressor substances. We tested the latter hypothesis by studying the effects of ouabain in the micromolar and nanomolar range on phenylephrine (PE)-evoked pressor responses. The experiments were performed in normotensive and hypertensive rats in vivo, under anesthesia, and in perfused rat tail vascular beds. The results showed that ouabain pretreatment increased the vasopressor responses to PE in vitro and in vivo. This sensitization after ouabain treatment was also observed in hypertensive animals which presented an enhanced vasopressor response to PE in comparison to normotensive animals. It is suggested that ouabain at nanomolar concentrations can sensitize vascular smooth muscle to vasopressor stimuli possibly contributing to increased tone in hypertension.
\end{abstract}

\section{Introduction}

Recently, ouabain has been described as an endogenous substance occurring in the nM range in the plasma of hypertensive subjects (1-3). These findings have strengthened the proposal that ouabain can increase vascular resistance and induce hypertension (4). Since ouabain inhibits the $\mathrm{Na}^{+}$-pump activity in vascular smooth muscle (VSM) cells, two consequences of this inhibition occur resulting from the intracellular $\mathrm{Na}^{+}$ increment (5-7). First, the membrane is depolarized $(8,9)$ and second, the $\mathrm{Na}^{+} / \mathrm{Ca}^{2+}$ exchanger activity is reduced $(6,7,10)$. Independent of either effect, the final result is the
Key words

- Ouabain

- $\mathrm{Na}^{+}$-pump

- Hypertension perfusion

- Arterial blood pressure

- Vascular reactivity

- Phenylephrine
- Rat tail vascular bed increase in intracellular $\mathrm{Ca}^{2+}$ concentration and an increase in vascular tone. This possibility suggests a putative role of ouabain as a pressor agent. Indeed, a direct ouabain vasoconstrictor effect has been reported (4) but only at high concentrations of this compound. However, a direct hypertensive effect produced by endogenous ouabain is unlikely since very low ouabain concentrations occur in plasma (1). Thus, another mechanism must be proposed to explain the pressor action.

The possible explanation for this effect is that ouabain acts on the $\alpha$-subunits of $\mathrm{Na}^{+}, \mathrm{K}^{+}-$ ATPase inhibiting $\mathrm{Na}^{+}$-pump activity $(11,12)$. $\mathrm{Na}^{+}, \mathrm{K}^{+}$-ATPase is an integral protein of the 
plasma membrane, a heterodimer composed of two subunits, a larger catalytic $\alpha$-subunit and a heavily glycosylated $\beta$-subunit $(11,12)$. This enzyme is a receptor for digitalis compounds that specifically inhibit its activity and occurs as multiple isoforms for $\alpha$ - and $\beta$ subunits with both high and low sensitivities to digitalis inhibition (13), according to their catalytic $\alpha_{1^{-}}, \alpha_{2^{-}}$or $\alpha_{3}$-subunits. Recent reports have indicated that the VSM displays all 3 types of $\alpha$-subunits of $\mathrm{Na}^{+}, \mathrm{K}^{+}$-ATPase $(14,15)$, including the high-affinity subunits $\alpha_{2}$ and $\alpha_{3}$ for ouabain. Consequently, differential effects will depend on the plasma concentration of circulating digitalis and also on the percentage of each enzyme isoform present in tissue.

Since the $\mathrm{Na}^{+}$-pump extrudes $\mathrm{Na}^{+}$from the cells its failure leads to the accumulation of intracellular $\mathrm{Na}^{+}$which is followed by an intracellular $\mathrm{Ca}^{2+}$ increment (6). Even if the initially induced myoplasmic $\mathrm{Ca}^{2+}$ increment is small, the amplifier action of the sarcoplasmic reticulum (SR) favors the possibility of an increased vascular tone upon activation $(3,16)$. Recently, it has been shown that even small increments of myoplasmic $\mathrm{Ca}^{2+}$ may increase vascular tone because of

Figure 1 - Typical tracings demonstrating the effects of $100 \mu \mathrm{M}$ and $10 \mathrm{nM}$ ouabain treatment on the phenylephrine (PE)-induced vasopressor changes in rat tail vascular beds from normotensive Wistar Kyoto (WKY) and hypertensive (SHR) rats. Observe the sensitization to the PE pressor response that occurs after ouabain treatment.

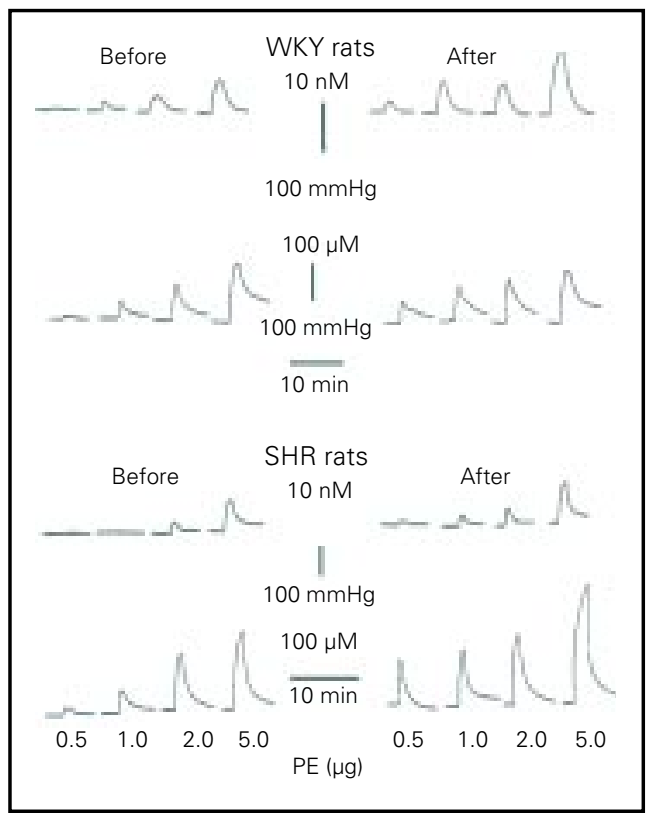

the amplifier action of the SR $(3,16)$. An indication of this possibility was reported with low ouabain concentrations $(10 \mathrm{nM})$, increasing the constrictor action of caffeine (17) on rat aortic rings and increasing the vasopressor responses to phenylephrine (PE) in the isolated rat tail vascular bed from normotensive and hypertensive rats (18-20). In a previous report we also showed that pretreatment with subtherapeutic doses of ouabain enhances PE vasopressor effects in anesthetized normotensive and hypertensive rats $(21,22)$. If this mechanism is operative small concentrations of ouabain would increase the vascular resistance by smooth muscle sensitization to vasopressor substances. This possibility suggests that circulating ouabain may increase vascular resistance by smooth muscle sensitization to vasopressor substances even at very low concentrations.

\section{Material and Methods}

\section{In vitro experiments}

Rat tail vascular beds obtained from normotensive male Wistar Kyoto (WKY) and spontaneously hypertensive (SHR) rats, weighing 300-400 g, were used in this study. Five to nine rats were used for each experimental group.

The day before the experiments the systolic blood pressure (SBP) of the rats was measured using the tail-cuff method (IITC Model 29 Pulse Amplifier, IITC Inc., CA).

For the perfusion experiments the rats were anesthetized with sodium pentobarbital $(35 \mathrm{mg} / \mathrm{kg}, i p)$ and received 100 units of heparin. The tail artery was then dissected and cannulated near the insertion of the tail using stretched PE 50 tubing. The preparations were perfused (Ismatec Reglo pump) with Krebs-Henseleit (KH) bicarbonate buffer solution, $\mathrm{pH} 7.4$, bubbled with $5 \%$ $\mathrm{CO}_{2}-95 \% \mathrm{O}_{2}$, containing $27.2 \mathrm{mM} \mathrm{NaHCO}_{3}$, $119 \mathrm{mM} \mathrm{NaCl}, 1 \mathrm{mM} \mathrm{NaH} \mathrm{PO}_{4}, 1.2 \mathrm{mM}$ 
$\mathrm{MgSO}_{4}, 2.5 \mathrm{mM} \mathrm{CaCl} 2.2 \mathrm{H}_{2} \mathrm{O}, 11 \mathrm{mM}$ glucose, $5 \mathrm{mM} \mathrm{KCl}$ and $0.03 \mathrm{mM}$ EDTA, at a constant flow of $2.5 \mathrm{ml} / \mathrm{min}$. After a 30 - to 45-min stabilization period the experimental protocol was initiated. Randomized bolus doses of phenylephrine $(0.5,1,2$ and $5 \mu \mathrm{g}$, in $0.1 \mathrm{ml}$ ) were injected and the developed pressure was measured with a COBE CDX pressure transducer connected to a Grass 7P16 preamplifier and recorded with a Grass 7 recorder. Since a constant flow was maintained the changes in pressure were a direct indication of vascular resistance. The preparations were then continuously perfused with KH plus ouabain $(100 \mu \mathrm{M}$ or $10 \mathrm{nM}$ for 30 min and $60 \mathrm{~min}$, respectively) and the same protocol was repeated.

\section{In vivo experiments}

Studies were performed in 22 male Wistar normotensive rats (NR), weighing 200 to $380 \mathrm{~g}$, and 24 SHR, weighing 190 to $350 \mathrm{~g}$.

The day before the experiments systolic blood pressure of the rats was measured using the tail-cuff method (IITC Model 29 Pulse Amplifier, IITC Inc.). Rats were anesthetized with urethane $(1.2 \mathrm{~g} / \mathrm{kg}$, ip $)$ supplemented when necessary. The jugular vein and the carotid artery were dissected for drug infusion and arterial blood pressure measurements. ECG was also measured using standard procedures.

Vasopressor reactivity was tested by injecting increasing concentrations of $\mathrm{PE}(0.1$, 0.25 and $0.5 \mu \mathrm{g}$ ) administered in small volumes ( $5 \mu \mathrm{l}$ or less), before and $1 \mathrm{~h}$ after ouabain treatment. The rats were divided into 3 groups and each group was submitted to one ouabain treatment, $18,1.8$ and 0.18 $\mu \mathrm{g} / \mathrm{kg}$, respectively, for $1 \mathrm{~h}$. SBP, diastolic blood pressure (DBP) and ECG were monitored continuously throughout the experiments.

Data were analyzed statistically by ANOVA and the Student $t$-test for small samples. A significant ANOVA was fol- lowed by Tukey's post hoc test. The results are reported as means \pm SEM and were considered to be significant at the 5\% level.

\section{Results}

\section{In vitro experiments}

Figure 1 shows the sensitizing effect of $100 \mu \mathrm{M}$ ouabain on PE-evoked vasoconstrictor responses in the tail vascular bed from normotensive and hypertensive rats. Before ouabain pretreatment the developed perfusion pressure increased with PE concentration. The continuous perfusion of 100 $\mu \mathrm{M}$ ouabain sensitized the vessels increasing the vasoconstrictor responses (20). However, since circulating ouabain concentration in the plasma of hypertensive subjects is approximately $10 \mathrm{nM}(1,2)$ the same protocol was repeated after 60 min pretreatment with $10 \mathrm{nM}$ ouabain in other tail vascular beds isolated from normotensive and hypertensive rats. A similar result is shown in Figure 1 where it is seen that the sensitization process occurred at a lower level after $10 \mathrm{nM}$ ouabain. It is interesting to note that normalizing the results obtained before and after $10 \mathrm{nM}$ ouabain the percentage increase in pressure was higher in SHR (Figure 2).

\section{In vivo experiments}

Normotensive rats $(\mathrm{SBP}=126 \pm 1.98$ $\mathrm{mmHg})$ and $\mathrm{SHR}(\mathrm{SBP}=177 \pm 3.76 \mathrm{mmHg})$ were used for these studies. Figure 3 shows the vascular reactivity represented by PEevoked pressor responses from NR and SHR pooled together before ouabain treatments. SHR displayed a higher systolic and diastolic blood pressure than NR and systolic PE-evoked pressor responses were higher in the SHR group.

\section{$18 \mu \mathrm{g} / \mathrm{kg}$ ouabain treatment}

SBP increased in both NR and SHR 
Figure 2 - Effect of $10 \mathrm{nM}$ ouabain percent changes above baseline perfusion pressure on phenylephrine-induced pressor responses in isolated perfused rat tail vascular beds from hypertensive (SHR) and normotensive Wistar Kyoto (WKY) rats. Points represent means \pm SEM. ${ }^{*} \mathrm{P}<0.05$ for comparison between before (triangles) and af ter (circles) $10 \mathrm{nM}$ ouabain treatment (ANOVA).
Figure 3 - Effect of phenylephrine $(P E)$ on the systolic blood pressure (SBP) and diastolic blood pressure (DBP) of normotensive (NR) and hypertensive (SHR) rats. ${ }^{*} \mathrm{P}<0.01$ for comparison between NR and SHR; $+P<0.01$ for comparison between PE and controls (ANOVA). groups after ouabain treatment $(18 \mu \mathrm{g} / \mathrm{kg})$ and SBP values were higher in the SHR group. PE pressor responses occurred for both groups but were higher in the SHR group. DBP values were also higher in the SHR group after ouabain treatment but similar for NR (Figure 4).
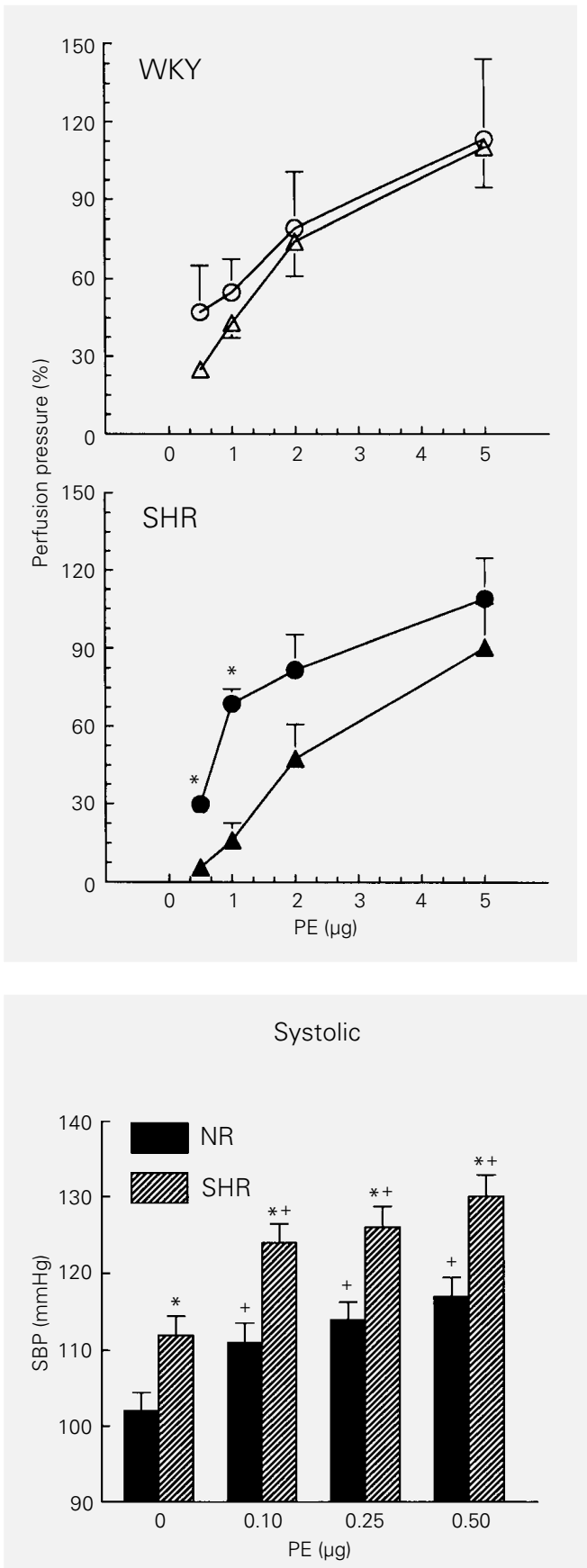

\section{$1.8 \mu \mathrm{g} / \mathrm{kg}$ ouabain treatment}

Figure 5 shows the changes of SBP and DBP in NR and SHR groups before and after ouabain treatment. In the NR group $\mathrm{PE}$ evoked similar pressor responses for both SBP and DBP before and after ouabain treatment. In contrast, SHR showed an increase in SBP and DBP after ouabain treatment and PE pressor effects were enhanced.

\section{$0.18 \mu \mathrm{g} / \mathrm{kg}$ ouabain treatment}

With this dose nanomolar levels of circulating ouabain might be attained and still produce similar effects as those observed with the $1.8 \mu \mathrm{g} / \mathrm{kg}$ ouabain dose (Figure 6). Again, very low doses of ouabain enhanced the PE-evoked pressor response of SHR, showing that these animals are more sensitive to ouabain.

\section{Discussion}

The existence of a plasma natriuretic factor that inhibits $\mathrm{Na}^{+}, \mathrm{K}^{+}$-ATPase has been suspected for many years. A few years ago ouabain, a steroid compound that has been identified in plasma and tissue extracts and in the adrenal cortex, has been suggested as the source of this compound (1-3).

Ouabain inhibits the $\mathrm{Na}^{+}$-pump by bind-
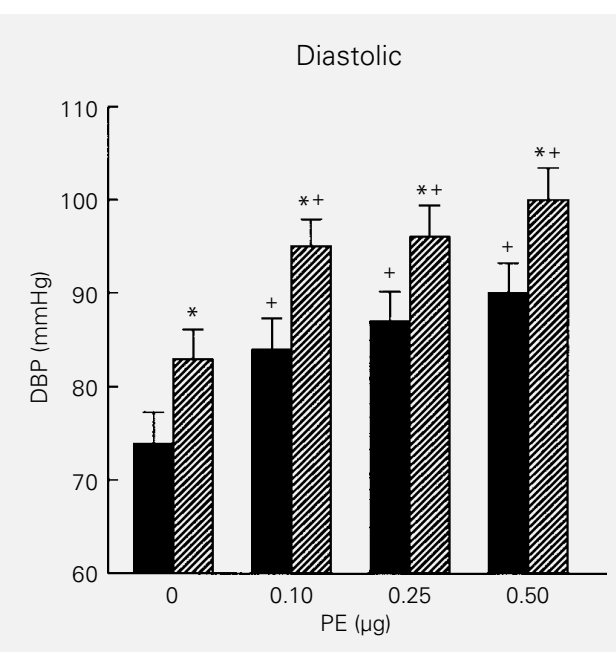


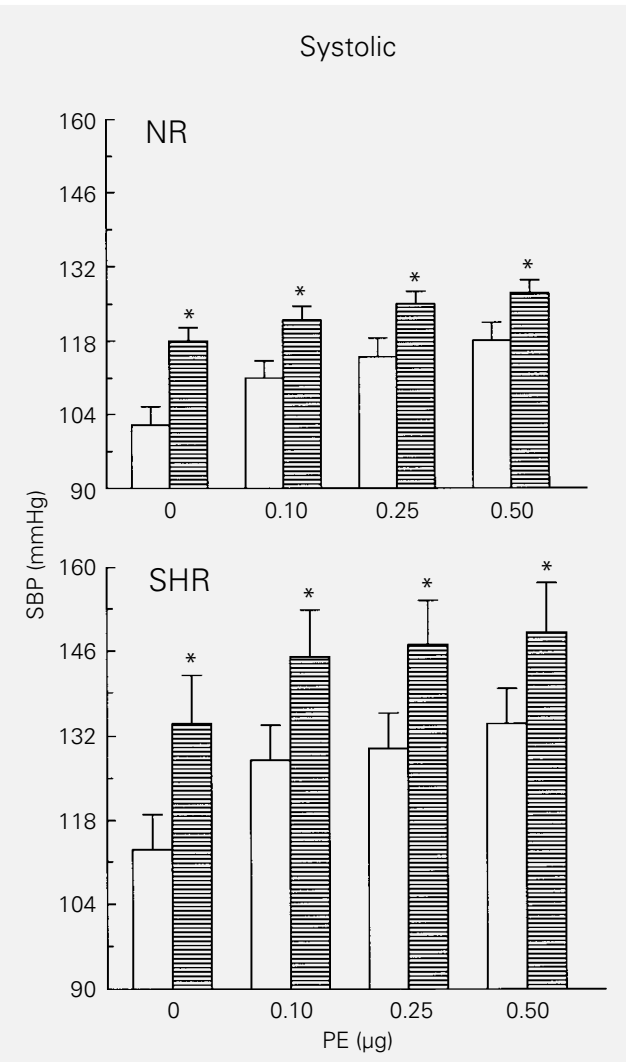

ing to the $\alpha$-subunits of the enzyme $(11,12)$. Since the heart, vessels, kidneys and nervous tissue carry at least two isoforms of the enzyme (12-14), profound effects on homeostatic mechanisms may be produced by ouabain. One of these mechanisms is the regulation of blood pressure. By inhibiting the $\mathrm{Na}^{+}$-pump of VSM ouabain increases the intracellular $\mathrm{Na}^{+}$concentration leading to two main effects, membrane depolarization and reduced $\mathrm{Na}^{+} / \mathrm{Ca}^{2+}$ exchanger activity (6-9). Both effects result in an increase in intracellular $\mathrm{Ca}^{2+}$ concentration and vascular tone. Having such actions ouabain could play a central role in the development of hypertension (23). Many reports suggested such a role since ouabain can produce hypertension during long-term administration in rats (4) and potentiate serotonin-evoked contractions of aortic rings (17). However, a direct pressor effect is unlikely since plasma ouabain concentrations occur at nanomolar levels
Diastolic

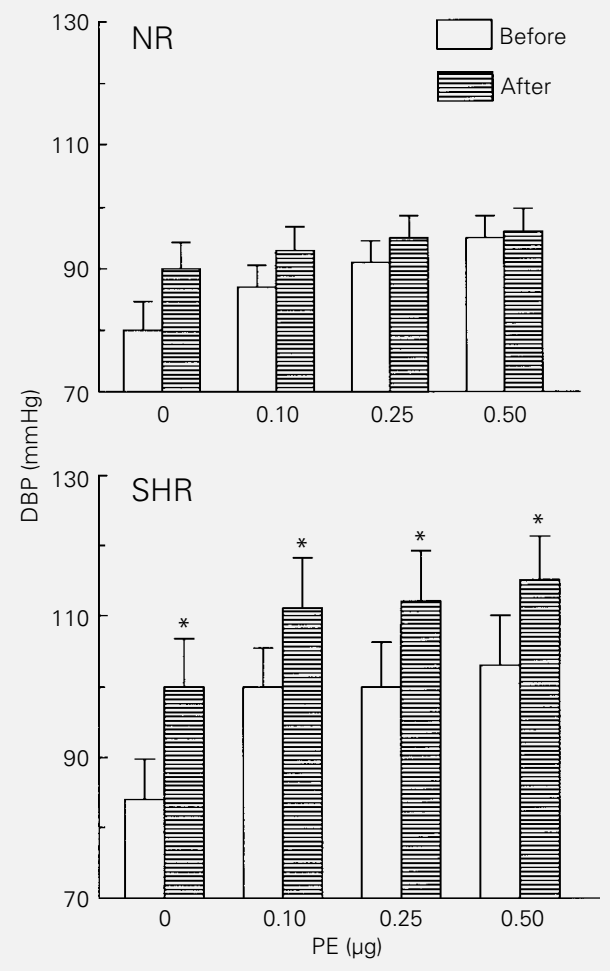

Figure 4 - Effects of increasing doses of phenylephrine (PE) on the systolic blood pressure (SBP) and diastolic blood pressure (DBP) of normotensive (NR) and hypertensive (SHR) rats before and after 1-h treatment with $18 \mu \mathrm{g} / \mathrm{kg}$ ouabain. Column height indicates the mean and the bar the SEM. ${ }^{*} P<0.05$ for comparison between before and after ouabain treatment (ANOVA).
(1). Despite these considerations, ouabain could also increase vascular tone by other mechanisms. Recently, it has been shown that small increments of myoplasmic $\mathrm{Ca}^{2+}$ may produce increased vascular tone because of the amplifier action of the SR $(3,16)$. The possibility of such occurrence has been shown recently with low ouabain concentrations $(10 \mathrm{nM})$ that increased caffeine-evoked contractions in rat aortic rings (17).

We tested the hypothesis that ouabain increases vascular resistance by smooth muscle sensitization to vasopressor substances using a perfused rat tail vascular bed preparation from normotensive and hypertensive rats. This preparation displayed an intrinsic basal tone and a high sensitivity to vasopressor substances. Also, since many in vitro experiments, both biochemical or physiopharmacological, have been performed with the rat tail artery, the present preparation permits a correlation between 
Figure 5 - Effects of increasing doses of phenylephrine (PE) on the systolic blood pressure (SBP) and diastolic blood pressure (DBP) of normotensive (NR) and hypertensive (SHR) rats before and after 1-h treatment with 1.8 $\mu \mathrm{g} / \mathrm{kg}$ ouabain. Column height indicates the mean and the bar the SEM. ${ }^{*} P<0.05$ for comparison between before and after ouabain treatment (ANOVA).

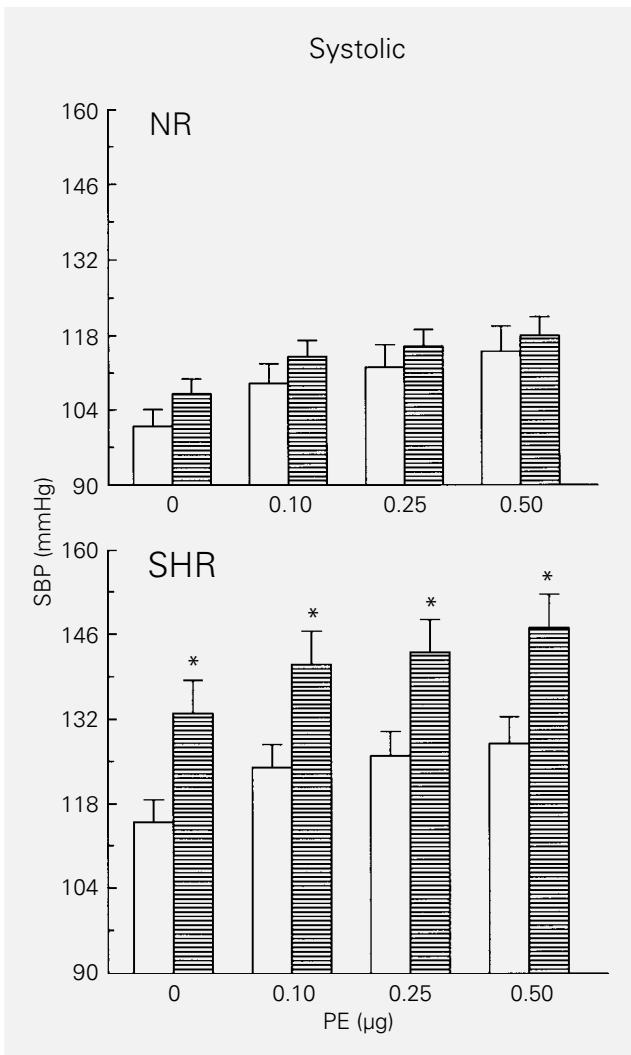

these studies and functional experiments $(14,24,25)$.

We also tested this hypothesis in vivo using anesthetized normotensive and hypertensive rats. The results showed that in both rat strains ouabain pretreatment affected the pressor responses to PE. Without any treatment SHR displayed higher values of SBP and DBP both before and after PE-evoked pressor responses.

All ouabain treatments increased SBP and DBP and enhanced PE-evoked pressor responses in SHR. However, NR only showed this response after $18 \mu \mathrm{g} / \mathrm{kg}$ ouabain treatment. The lower doses $(1.8$ and $0.18 \mu \mathrm{g} / \mathrm{kg}$, subtherapeutic doses) did not change the arterial blood pressure and had no effects on the PE-evoked pressor responses. These results suggest that a) SHR display higher arterial blood pressure levels than NR even during PE-evoked pressor responses, b) ouabain sensitizes SHR and NR to PE-evoked pressor responses when therapeutic doses are used, and c) subtherapeutic doses of ouabain only show effects in the SHR strain.

The expression of $\mathrm{Na}^{+}, \mathrm{K}^{+}$-ATPase and its $\alpha$-isoform is known to be regulated by multiple factors such as developmental stages (26), hormones (27) and the occurrence of hypertension (15). Also, it has been shown that $\alpha$-subunits of $\mathrm{Na}^{+}, \mathrm{K}^{+}$-ATPase consist of different $\alpha_{1^{-}}, \alpha_{2^{-}}$and $\alpha_{3^{-}}$-subunits with different affinities for digitalis (13). Since the $\mathrm{Na}^{+}, \mathrm{K}^{+}$-ATPase isoforms may change in several situations, the maintenance of the sensitizing mechanism could be of clinical relevance. In the present study we investigated if the sensitization mechanism is operative in normotensive and hypertensive rats. The results presented here suggest that the sensitization mechanism is operative in both normotensive and hypertensive animals.

A possible explanation for this behavior may be the existence of a similar or increased abundance of the $\alpha_{3}$-isoform in both normotensive and hypertensive rat tail vas- 


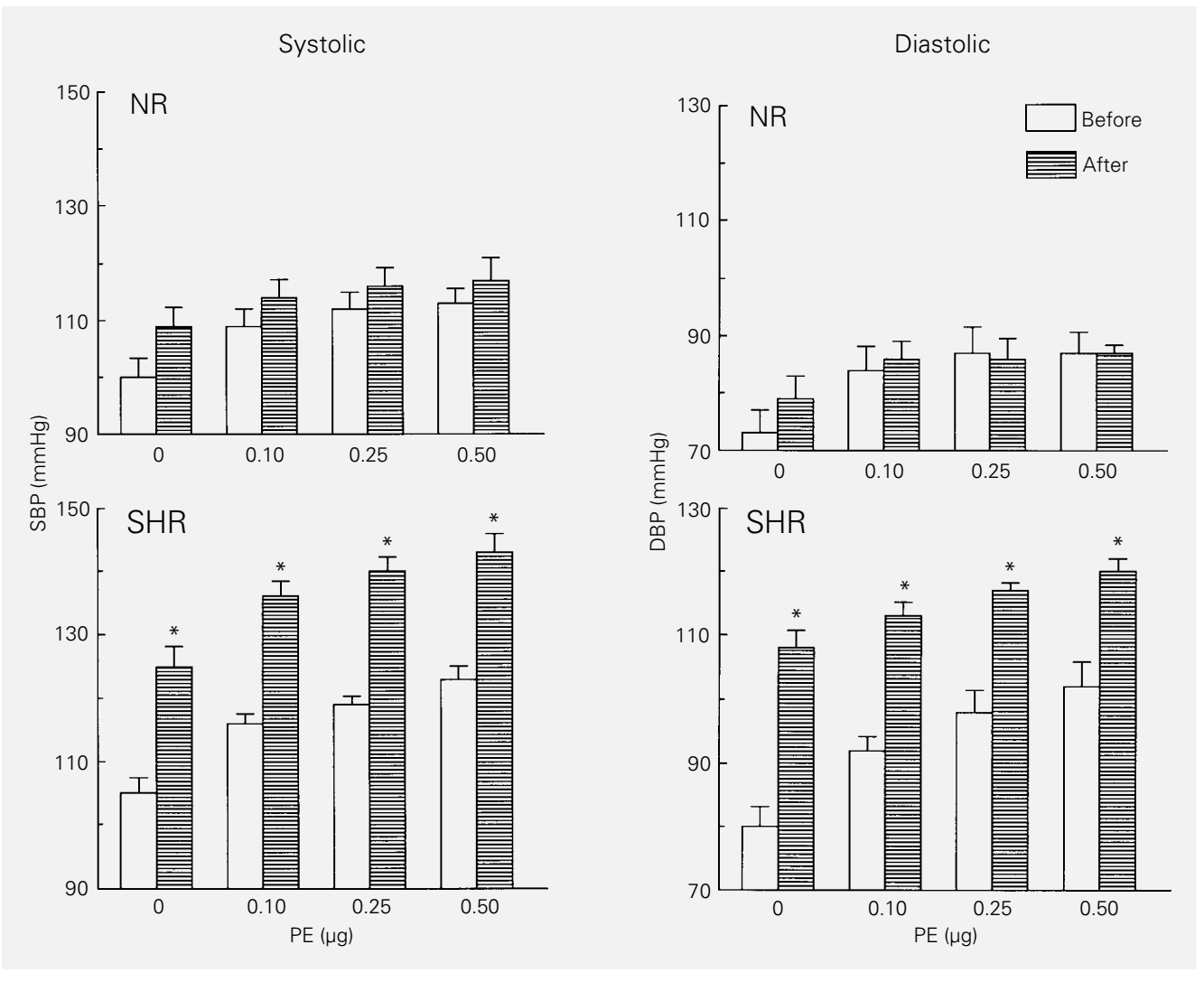

Figure 6 - Effects of increasing doses of phenylephrine (PE) on the systolic blood pressure (SBP) and diastolic blood pressure (DBP) of normotensive (NR) and hypertensive (SHR) rats before and after 1-h treatment with $0.18 \mu \mathrm{g} / \mathrm{kg}$ ouabain. Column height indicates the mean and the bar the SEM. ${ }^{*} \mathrm{P}<0.05$ for comparison between before and after ouabain treatment (ANOVA). cular beds since ouabain binds preferentially to this isoform. However, to our knowledge only Songu-Mize et al. (28) and Herrera et al. (15) presented evidence showing upregulation of the $\mathrm{Na}^{+}$-pump activity and of $\alpha_{1^{-}}$ mRNA in the rat tail artery and aorta, respectively, together with a downregulation of the $\alpha_{2}$-mRNA as a result of DOCA-salt hypertension. An increase in the activity of the $\mathrm{Na}^{+}$-pump would favor relaxation during hypertension. This increased activity even resulting from the $\alpha_{1}$-isoform may be inhibited by ouabain at levels sufficient to produce or maintain the sensitization mechanism. Our results, however, cannot discriminate which mechanism is responsible for this sensitization effect.

We conclude that the sensitization process to vasopressor substances that occurs at nanomolar ouabain concentrations in plasma is operative even in hypertensive animals and may contribute to the increase and maintenance of vascular tone in hypertension.

\section{References}

1. Hamlyn JM, Blaustein MP, Bova S, DuCharme DW, Harris DW, Mandel F, Mathews WR \& Ludens JH (1991). Identification and characterization of an ouabain-like compound from human plasma. Proceedings of the National Academy of Sciences, USA, 88: 6259-6263.

2. Ludens JH, Clark MA, Robinson FG \& DuCharme DW (1992). Rat adrenal cortex is a source of a circulating ouabain-like compound. Hypertension, 19: 721-724.
3. Blaustein MP (1993). Physiological effects of endogenous ouabain: control of intracellular $\mathrm{Ca}^{2+}$ stores and cell responsiveness. American Journal of Physiology, 264: C1367-C1387.

4. Yuan CM, Manunta P, Hamlyn JM, Chen S, Bohen E, Yeun J, Haddy FJ \& Pamnani MB (1993). Long-term ouabain administration produces hypertension in rats. $\mathrm{Hy}$ pertension, 22: 178-187.
5. Goto A, Yamada K, Yagi N, Yoshioka M \& Sugimoto T (1992). Physiology and pharmacology of endogenous digitalis-like factors. Pharmacological Reviews, 44: 377399.

6. Blaustein MP (1988). Sodium/calcium exchange and the control of contractility in cardiac muscle and vascular smooth muscle. Journal of Cardiovascular Pharmacology, 12 (Suppl): S56-S68. 
7. Blaustein MP, Goldman WF, Fontana G, Krueger BK, Santiago EM, Steele TD, Weiss DN \& Yarowsky PJ (1991). Physiological roles of the sodium-calcium exchanger in nerve and muscle. Annals of the New York Academy of Sciences, 639: 254-274.

8. Fleming WW (1980). The electrogenic $\mathrm{Na}^{+}, \mathrm{K}^{+}$-pump in smooth muscle: physiologic and pharmacologic significance. Annual Review of Pharmacology and Toxicology, 20: 129-149.

9. Mulvany MJ (1984). Effect of electrolyte transport on the response of arteriolar smooth muscle. Journal of Cardiovascular Pharmacology, 6: S82-S87.

10. Rembold $\mathrm{CM}$, Richard $\mathrm{H}$ \& Chen $\mathrm{XL}$ (1992). $\mathrm{Na}^{+}-\mathrm{Ca}^{2+}$ exchange, myoplasmic $\mathrm{Ca}^{2+}$ concentration, and contraction of arterial smooth muscle. Hypertension, 19: 308-313.

11. Skou JC \& Esmann M (1992). The Na,KATPase. Journal of Bioenergetics and Biomembranes, 24: 249-261.

12. Lingrel JB (1992). Na, K-ATPase: isoform structure, function, and expression. Journal of Bioenergetics and Biomembranes, 24: $263-270$

13. Sweadner KJ (1989). Isozymes of the $\mathrm{Na}^{+}$/ $\mathrm{K}^{+}$-ATPase. Biochimica et Biophysica Acta, 988: 185-220.

14. Sahin-Erdemli I, Rashed SM \& SonguMize E (1994). Rat vascular tissues express all three $\alpha$-isoforms of $\mathrm{Na}^{+}-\mathrm{K}^{+}$ATPase. American Journal of Physiology, 266: H350-H353.

15. Herrera VLM, Chobanian AV \& Ruiz-Opazo $N$ (1988). Isoform specific modulation of $\mathrm{Na}^{+}, \mathrm{K}^{+}$-ATPase alpha-subunit gene expression in hypertension. Science, 241: 221-223.
16. Blaustein MP, Ambesi A, Bloch RJ, Goldman WF, Juhaszova M, Lindenmayer GE \& Weiss DN (1992). Regulation of vascular smooth muscle contractility: Roles of the sarcoplasmic reticulum (SR) and the sodium/calcium exchanger. Japanese Journal of Pharmacology, 58 (Suppl 2): 107P-114P.

17. Weiss DN, Podberesky DJ, Heidrich J \& Blaustein MP (1994). Nanomolar ouabain augments caffeine-evoked contractions in rat arteries. American Journal of Physiology, 265: C1443-C1448.

18. Vassallo DV, Rashed S, Varner K \& SonguMize E (1994). Differential effect of ouabain on modulation of vascular reactivity in normotensive and hypertensive rats. FASEB Journal, 8: A300, Abstract 1735.

19. Songu-Mize E, Vassallo DV, Rashed SSK \& Varner KJ (1994). Very low concentration of ouabain enhances the phenylephrine-induced contractions in normotensive and hypertensive rat tail arteries. Hypertension, 24: 384, Abstract 68.

20. Songu-Mize E, Vassallo DV, Rashed SM \& Varner K (1995). Ouabain amplifies contractile responses to phenylephrine in rat tail arteries in hypertension. Journal of Basic and Clinical Physiology and Pharmacology, 6: 309-318.

21. Amaral SMC, Rossoni LV, Pinto VD \& Vassallo DV (1995). Efeito da ouabaína sobre a resposta vasopressora da fenilefrina em ratos normotensos. Anais da $X$ Reunião Anual da FESBE, Abstract 8.50.

22. Rossoni LV, Amaral SMC, Pinto VD \& Vassallo DV (1995). Efeito da ouabaína sobre a resposta vasopressora da fenilefrina em ratos hipertensos SHR. Anais da X Reunião Anual da FESBE, Abstract 8.49 .
23. Blaustein MP \& Hamlyn JM (1991). Pathogenesis of essential hypertension. A link between dietary salt and high blood pressure. Hypertension, 18 (Suppl III): III.184III.195.

24. Songu-Mize E (1991). Vascular sodium pump activity kinetics in early and advanced stages of deoxycorticosterone-salt hypertension in rats. Life Sciences, 49: 2045-2052.

25. Songu-Mize E, Caldwell RW \& Baer PG (1987). High and low dietary potassium effects on rat vascular sodium pump activity. Proceedings of the Society for Experimental Biology and Medicine, 186: 280-287.

26. Orlowski J \& Lingrel JB (1988). Tissuespecific and developmental regulation of rat $\mathrm{Na}^{+}, \mathrm{K}^{+}-$ATPase catalytic $\alpha$ isoform and B subunit mRNAs. Journal of Biological Chemistry, 263: 10436-10442.

27. Horowitz BC, Hensley CB, Quintero M Azuma KK, Putnam D \& McDonough AA (1990). Differential regulation of $\mathrm{Na}^{+}, \mathrm{K}^{+-}$ ATPase alpha 1, alpha 2, and beta subunit mRNA and protein levels by thyroid hormone. Journal of Biological Chemistry, 265: 14308-14314.

28. Songu-Mize E, Bealer SL \& Caldwell RW (1987). Effect of DOCA-salt treatment duration and anteroventral third ventricle lesions on a plasma-borne sodium pump inhibitor. Journal of Hypertension, 5: 461467. 